\title{
Polycythaemia due to Excess Erythropoetin Production
}

National Cancer Institute

\section{Source}

National Cancer Institute. Polycythaemia due to Excess Erythropoetin Production. NCI

Thesaurus. Code C35434.

Polycythemia that is caused by excess erythropoietin. 